Revista de la red interuniversitaria de estudios sobre las literaturas rioplatenses contemporáneas en Francia

$6 \mid 2011$

Juan José Saer. archivos, memoria, critica

\title{
Con un pie en el estribo
}

Mariana Di Ció y Valentina Litvan

\section{OpenEdition}

\section{Journals}

\section{Edición electrónica}

URL: http://journals.openedition.org/lirico/116

DOI: $10.4000 /$ lirico. 116

ISSN: 2262-8339

Editor

Réseau interuniversitaire d'étude des littératures contemporaines du Río de la Plata

\section{Edición impresa}

Fecha de publicación: 1 diciembre 2011

Paginación: 15-17

ISBN: 2-9525448-5-9

ISSN: 2263-2158

\section{Referencia electrónica}

Mariana Di Ció y Valentina Litvan, « Con un pie en el estribo », Cuadernos LIRICO [En línea], 6 | 2011, Publicado el 01 julio 2012, consultado el 22 septiembre 2020. URL : http://journals.openedition.org/ lirico/116 ; DOI : https://doi.org/10.4000/lirico.116

\section{(ब) $\odot \Theta$}

Cuadernos LIRICO está distribuido bajo una Licencia Creative Commons Atribución-NoComercialSinDerivar 4.0 Internacional. 


\section{CON UN PIE EN EL ESTRIBO}

E

l presente volumen recoge una selección de las ponencias leídas durante el coloquio internacional "Saer: archives, mémoires, critique", que tuvo lugar en la Maison de l'Argentine (Cité Universitaire de Paris) a comienzos de junio de 2010,organizado conjuntamente por las siguientes instituciones y equipos de investigación: la Universidad de Bretagne Sud-Lorient (eje "Culture populaire et culture savante dans les Amériques" del laboratorio Héritages et Constructions dans le Texte et l'Image, EA 4249; responsable: Rémi Le Marc'hadour), la Université Paris 8-Vincennes-Saint-Denis (equipo "Amérique latine contemporaine: littérature et socio- histoire" del laboratorio Études Romanes, EA 4385; responsables: Françoise Decroisettte y Julio Premat) y la Universidad Nacional de La Plata (proyecto de Investigación Plurianual "Juan José Saer: archivos, memoria, crítica", IdIHCS, UNLP-CONICET; responsable: Miguel Dalmaroni). El comité de organización del coloquio estuvo compuesto por Sergio Delgado, Mariana Di Ció, Pénélope Laurent, Valentina Litvan, Julio Premat, Diego Vecchio y Graciela Villanueva, y contó con la participación del Institut des Amériques y de la Maison de l'Argentine.

Los doce artículos aquí publicados constituyen una muestra de las comunicaciones leídas tanto por investigadores jóvenes como consolidados, procedentes de diversas instituciones: estuvieron representadas universidades francesas, argentinas y norteamericanas. De alguna manera, reproduce el intercambio y el diálogo entre generaciones y procedencias académicas que tuvo lugar durante el coloquio, uno de cuyos objetivos principales era, precisamente, alimentar la actualidad de las conversaciones saerianas en torno a la noción de archivo. Las dos secciones en que hemos dividido estas actas pretenden dar cuenta de una división espontánea, esbozada ya en el coloquio, entre los ponentes que presentaron trabajos sobre la obra édita de Juan José Saer y los que hicieron un estudio genético a partir de sus manuscritos. De inspiración saeriana, los títulos de cada sección responden a esta doble vertiente de la crítica. 
En "Discusiones en el cancel del verano", todos los autores presentan lecturas -ya sea puntuales o transversales- de la obra publicada. Por su particular modo de orquestrarse, como conjunto de fragmentos que se van modelando y redefiniendo a partir de cada nuevo texto, como polémica unidad en la diversidad, o como una totalidad acabada pero paradójicamente inconclusa, la obra de Saer incita a una reflexión más amplia, acerca de los límites de la noción de obra. El fin y el principio parecen ser nociones que enmarcan este interrogante, desde las primeras puestas en escena de la escritura por personajes de juventud en el artículo que abre el volumen (Cristina Iglesia) hasta la "génesis del final" que propone Dardo Scavino, en un artículo que permite la transición hacia la segunda sección. Entre uno y otro, se adelantan lecturas en las que cada texto de Saer sería fragmento luminoso de una totalidad incompleta (Pénélope Laurent) o en las que el lector/ espectador observa "instantáneas" (Florencia Amorena). Por su parte, Juan Carlos Mondragón sigue y persigue la construcción y evolución de los distintos personajes en sus reapariciones a lo largo de las distintas obras, acompañando la evolución del propio autor, mientras que Edgardo Dobry analiza el modo en que Saer se apropia del ritmo de la lírica para leer y situarse en la tradición.

La propuesta de Graciela Villanueva sobre incipits y excipits confunde el inicio de la segunda sección ("El rasguido de la pluma") con el final de la primera. Este segundo conjunto de ponencias recoge lecturas de la obra a la luz de los archivos del escritor, es decir, de los borradores, papeles preparatorios, inéditos y otro material genético. Al hacer posible la lectura de textos poco visibles hasta ahora, estos trabajos anuncian la edición de los manuscritos, en la que muchos de estos investigadores participan y que Julio Premat presenta en los dos anexos que cierran el volumen. Daniel Balderston estudia minuciosamente las variantes y desviaciones de una serie de traducciones de poesía norteamericana, mientras que, cada uno a su manera, Sergio Delgado y Valentina Litvan trabajan la idea del viaje y de la errancia como metáforas del proceso creativo, ya sea en la escritura de las libretas de viaje o en el pasaje de un texto a otro, respectivamente Mariana Di Ció estudia el dossier genético de La ocasión, y la posible relación entre la novela y un relato inacabado de los sesenta que lleva el mismo título. Se cierra la sección con el trabajo de Julio Premat sobre La grande, obra en la que Saer trabajaba al momento de su muerte, y cuyo carácter inconcluso deja abierto un espacio de hipótesis, especulaciones y conjeturas, que no hace sino reforzar la coherencia de la misma obra saeriana. 
Tras los artículos, adjuntamos, entonces, una sección final donde, a modo de postfacio, Julio Premat presenta algunas reflexiones de orden general acerca del trabajo con archivos y del modo en que la edición de textos inacabados o inéditos afecta al conjunto de la obra ya publicada. Le siguen una breve presentación del proyecto editorial sobre el fondo Juan José Saer, y el anexo "La mesa del escritor", que reproduce el material de lectura frecuentado por el autor durante la preparación de La grande. Por último, este volumen inaugura una sección fija de la nueva etapa de estos Cuadernos Lírico, a cargo de Martín Arias y de Enrique Schmuckler, que presenta reseñas de las últimas novedades editoriales en el ámbito de la literatura rioplatense.

Mariana Di Ció

VALENTINA LiTVAN 